Objectives: The objective of this work was to characterize the pharmacokinetics of ABT-494 with the extended-release formulation that is currently being utilized in Phase 3.

Methods: Comparison of ABT-494 pharmacokinetics from the immediate-release and extended-release formulations was conducted following multiple-dose administration in healthy subjects. Two cohorts of subjects were evaluated. In the first cohort, healthy subjects $(\mathrm{N}=12)$ received multiple $15 \mathrm{mg} \mathrm{QD}$ doses of the extended-release tablet formulation and multiple $6 \mathrm{mg}$ BID doses of the immediate-release capsule formulation for 7 days. In the second cohort, healthy subjects $(\mathrm{N}=12)$ received multiple $30 \mathrm{mg}$ QD doses of the extended-release tablet formulation and multiple $12 \mathrm{mg}$ BID doses of the immediate-release capsule formulation for 7 days. Both evaluations were conducted following an open-label, randomized, 2-period, 2-sequence, crossover design under fasting conditions. ABT-494 plasma concentrations were measured and pharmacokinetic parameters were calculated using non-compartmental analyses.

Results: At steady-state, ABT-494 AUC0-24 ratio [and 90\% confidence interval] was 0.94 [0.84 - 1.05], $C_{\max }$ ratio was 0.91 [0.74 -1.12 ] and $C_{\min }$ ratio was 1.09 [0.85 - 1.40] for the $15 \mathrm{mg}$ QD regimen of the extended-release formulation relative to the $6 \mathrm{mg}$ BID regimen of the immediate-release formulation. Similarly, ABT-494 mean $\mathrm{AUC}_{0-24}$ ratio was 0.97 [0.87 - 1.09], $\mathrm{C}_{\max }$ ratio was 0.90 [0.73 - 1.11] and $\mathrm{C}_{\min }$ ratio was 0.87 [0.75 - 1.02] for the $30 \mathrm{mg}$ QD regimen of the extended-release formulation relative to the $12 \mathrm{mg}$ BID regimen. All evaluated regimens were well-tolerated by healthy subjects.

Conclusions: ABT-494 regimens of $15 \mathrm{mg}$ QD and $30 \mathrm{mg}$ QD of the extendedrelease formulation, currently being utilized in Phase 3 RA studies, provide similar exposures to $6 \mathrm{mg}$ BID and $12 \mathrm{mg} \mathrm{BID}$, respectively of the immediate-release capsule formulation previously shown to provide optimal benefit-risk profiles in RA Phase 2 trials.

Disclosure of Interest: M.-E. Mohamed Shareholder of: AbbVie, Employee of: AbbVie, J. Zeng Shareholder of: AbbVie, Employee of: AbbVie, I.-H. Song Shareholder of: AbbVie, Employee of: AbbVie, A. Othman Shareholder of: AbbVie, Employee of: AbbVie

DOI: 10.1136/annrheumdis-2017-eular.3224

\section{THU0178 LONG TERM SAFETY PROFILE OF METHOTREXATE IN PATIENTS WITH RA IN ROUTINE CARE}

A.B. Nalawade ${ }^{1}$, S.M. Akerkar ${ }^{2}$, B.D. Pandey ${ }^{3} .{ }^{1}$ Rheumatology, Sancheti Institute, Pune; ${ }^{2}$ Mumbai arthritis clinic, Mumbai; ${ }^{3}$ Rheumatology, Fortis Hospital, Delhi, India

Background: Methotrexate is the anchor drug used most widely as monotherapy or combination therapy with other DMARDS \& biologics in treatment of RA. It is widely perceived by clinicians to have potentially dangerous adverse effects $(A E)$. The present study was designed to assess safety of long term methotrexate in patients with RA on standard care in clinical practice.

Objectives: To evaluate the safety of long term methorexate therapy in patients with RA

Methods: RA patients on methotrexate therapy at recommended doses (15-25 mg per week) as monotherapy or in combination with other conventional dmards or biologics for over 4 years were enrolled between Jan 2016 to Dec 2016. Since the objective was to assess safety, those patients initiated on methotrexate 4 years ago but had discontinued due to adverse effects were also included. Patients were analysed with a questionnaire and review of past records from the clinic. The questionnaire included questions about duration and compliance of methotrexate therapy, any untoward effects that patient felt were due to methotrexate and direct questions related to known methotrexate side effects. Investigations were reviewed from past records. Data were presented by 1 - year intervals starting from the time patient received first dose of methotrexate. Adverse events (AE), rate of discontinuation and abnormal laboratory results were analysed per 100 patient (pt.) years in 1 year intervals.

Results:

\begin{tabular}{lc}
\hline Females, no. $(\%)$ & $205(89.9 \%)$ \\
\hline Age, mean \pm SD (years) & $48.6( \pm 10.8)$ \\
Disease duration, mean \pm SD (years) & $8.4( \pm 5)$ \\
Seropositive (RF and/ or ACPA) & $207(91 \%)$ \\
Methotrexate monotherapy $(\%)$ & $55(24 \%)$ \\
\hline
\end{tabular}

The cumulative exposure to methotrexate was 926 patient years. Of 228 patients, 218 continued methotrexate through 4 years. Overall 10 patients discontinued methotrexate over 4 years, 5 due to $\mathrm{Gl}$ intolerance and 1 due skin allergy in the first year. In subsequent years 2 patients were withdrawn due to chronic cough, 1 due to raised transaminases and 1 patient after severe infection and pancytopenia. Incidence of AEs, severe AEs, infections, laboratory abnormalities and discontinuations due to AE's declined during 4 years exposure. The most common AEs included nausea and dyspepsia (24.6/ 100 pt. years in first year with declining incidence through 4 years). The second most common AE reported was infections (7/100 pt. years). Most common infections were mild UTI \& respiratory tract infections.14 patients initially asymptomatic or having mild nausea reported significantly increased nausea in year 4 and beyond, all responding to reduction of methotrexate dose. The incidence of severe AE that needed hospitalisation \&/ or discontinuation of methotrexate was $2.6 / 100$ pt. years in year 1 with declining events over time. The cumulative risk of serious AE over 4 years was 1.2/ 100 pt. years.

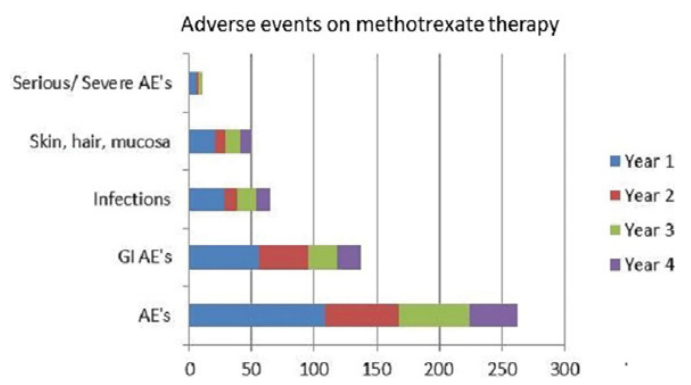

Conclusions: Methotexate therapy was well tolerated over 4 years treatment period with a good safety profile. Most of the AE's were mild to moderate severity not needing discontinuation of methotrexate. Study has limitations since it is retrospective observational study with small patient number from two outpatient rheumatology clinics. Some AE's may have been underestimated as patient compliance not ascertained and patients with AE's may have lost to follow up. Some effects may have been overestimated as precise causality is not proven. During the 4 years methotrexate treatment, no new safety concerns emerged. Disclosure of Interest: None declared DOI: 10.1136/annrheumdis-2017-eular.4055

\section{THU0179 INCIDENCE OF DEEP VEIN THROMBOSIS AFTER TOTAL HIP REPLACEMENT IN PATIENTS WITH RHEUMATOID ARTHRITIS}

A. Rybnikov, E. Byalik, S. Makarov, T. Reshetnyak, A. Khramov, E. Naryshkin, D. Ivanov, V. Pavlov. Orthopaedic, V.A. Nasonova research institute of rheumatology, Moscow, Russian Federation

Background: The purpose of this study was to compare incidences of VTE in patients with rheumatoid arthritis (RA) and osteoarthritis (OA) after total hip arthroplasty, different strategies for prevention of VTE and evaluate their efficiency. Objectives: To evaluate the efficiency of prevention of VTE in patients with rheumatoid arthritis and osteoarthritis after total hip replacement under comparable conditions.

Methods: A one-year prospective cohort study was performed on 173 primary THA patients operated in V.A. Nasonova Research Institute of Rheumatology for the period 2016. Of these, 91 patients with RA $(52.6 \%)$ and 82 patients with OA $(47.4 \%)$. For a comparative analysis of the efficiency of anticoagulant therapy, each patient group was divided into 2 subgroups by type of drug therapy. The first - nadroparin calcium (the drug therapy was started for 12 hours after the operation at a dose of $0.1 \mathrm{ml}$ per $10 \mathrm{~kg}$ of body weight one time per day), the second - nadroparin calcium with transfer to dabigatran etexilate (the first stage of 4 hours after the operation was started therapy by nadroparin calcium, and then after the removal of the epidural catheter moved to the dabigatran etexilate).Doppler ultrasonography (DUS) was routinely performed preoperatively and on postoperative day 7,14 , then 1 time a month for diagnosing a deep venous thrombosis (DVT). Time of observation was 6 months.

Results: DVT were reported in $8(4.8 \%)$ patients, 2 of them $(1.2 \%)$ with RA and $6(3.4 \%)$ with OA. Distal DVT developed on 8 and 17 days after total hip replacement in RA patient's group. They received nadroparin calcium only. 5 patients with VTE after surgery from OA group used nadroparin calcium and 1 patient was on combined drug therapy. Of the 8 cases of VTE - $6(75 \%)$ were asymptomatic and $2(25 \%)$ with development of clinical and laboratory picture. All cases of thrombosis in a group of RA was asymptomatic. In a perioperative period of clinically significant bleeding was not seen.

Conclusions: Cases of VTE in patients with RA, despite the large number of risk factors, under comparable conditions is significantly lower than patients with $\mathrm{OA}$. The number of asymptomatic DVT dominates symptomatic both comparison groups. In patients with RA and OA who were from the first group have reported 6 cases of VTE and only 1 case of VTE have reported in patients who were from second group. Prevention of VTE by combination of LMWH and NOACs was more effective and safety in RA and OA patients.

Disclosure of Interest: None declared

DOI: 10.1136/annrheumdis-2017-eular.6422

\section{THU0180 SYSTEMS BASED INVESTIGATION OF THE ANTI-IMMUNOGENIC POTENTIAL OF DMARDS FOR RHEUMATOID ARTHRITIS USING HUMAN PRIMARY CELL-BASED BIOMAP ${ }^{\circledR}$ PHENOTYPIC PROFILING}

A. O'Mahony ${ }^{1}$, E. Choy ${ }^{2}$. ${ }^{1}$ BioMAP Division, DiscoverX Corporation, South San Francisco, United States; ${ }^{2}$ Division of Infection and Immunity, Cardiff University School of Medicine, Cardiff, United Kingdom

Background: Biologics represent a rapidly growing class of approved and investigational drugs routinely used to treat multiple diseases, including inflammatory and rheumatic diseases ${ }^{1}$. Unfortunately, the success of such therapeutics is 